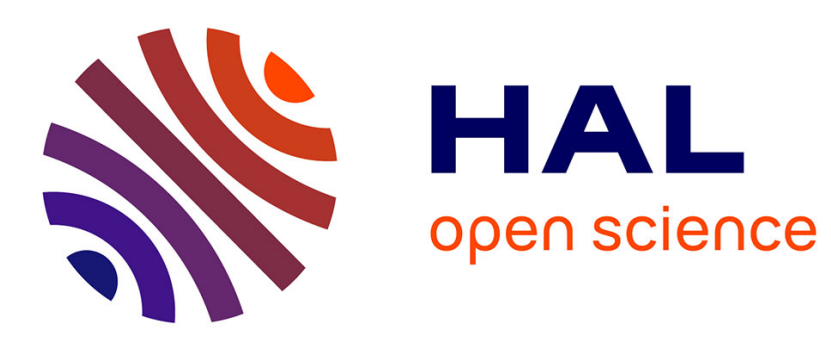

\title{
The failure of iron oxide scales at growth temperature under tensile stress
}

\author{
M. Nagl, W. Evans, D. Hall, S. Saunders
}

\section{To cite this version:}

M. Nagl, W. Evans, D. Hall, S. Saunders. The failure of iron oxide scales at growth temperature under tensile stress. Journal de Physique IV Proceedings, 1993, 03 (C9), pp.C9-933-C9-941. 10.1051/jp4:1993996 . jpa-00252438

\section{HAL Id: jpa-00252438 https://hal.science/jpa-00252438}

Submitted on 1 Jan 1993

HAL is a multi-disciplinary open access archive for the deposit and dissemination of scientific research documents, whether they are published or not. The documents may come from teaching and research institutions in France or abroad, or from public or private research centers.
L'archive ouverte pluridisciplinaire HAL, est destinée au dépôt et à la diffusion de documents scientifiques de niveau recherche, publiés ou non, émanant des établissements d'enseignement et de recherche français ou étrangers, des laboratoires publics ou privés. 


\title{
The failure of iron oxide scales at growth temperature under tensile stress
}

\author{
M. $\operatorname{Nagl}\left({ }^{1}\right)$, W.T. Evans $\left({ }^{1}\right)$, D.J. Hall $\left({ }^{2}\right)$ and S.R.J. Saunders $\left({ }^{2}\right)$
}

( $\left.{ }^{1}\right)$ University of Glamorgan, Dept. of Mech. \& Manuf. Eng., Treforest, Mid Glamorgan, CF37 1DL, U.K.

$\left({ }^{2}\right)$ National Physical Laboratory, Division of Materials Metrology, Teddington, Middlesex, TW11 OLW, U.K.

\begin{abstract}
Acoustic Emission (AE) was used to study the fracture of oxide grown on mild steel. Samples were oxidised and mechanically deformed in air at $550^{\circ} \mathrm{C}$ using strain rates of $\sim 10^{-4}$ and $10^{-5} \mathrm{~s}^{-1}$ in a bend test furnace having a ceramic 4-point bend jig. The results were compared with earlier observations made on oxides deformed at room temperature. In both cases equidistant cracks formed and the crack spacing decreased with increasing oxide thickness in agreement with a model based on interfacial slip. The adhesive strength of the oxide was lower and delamination was more evident at the growth temperature. The critical strains for failure were determined and compared with model predictions. In this context the voidage of the oxide scale appeared to be the single most important parameter and a $K_{\mathrm{IC}}$-value of $1.1 \mathrm{MN}$ $\mathrm{m}^{-3 / 2}$ was obtained for iron oxide up to $550^{\circ} \mathrm{C}$.
\end{abstract}

\section{Introduction.}

Components operating at high temperature are frequently subjected to mechanical and chemical attack arising from the operating conditions. In most cases a protective oxide layer reduces the degradation rate of the component. However, oxide scales which are ceramic materials, and thus do not have the ductility of the underlying metal [1] are prone to mechanical failure (cracking) and hence the environment regains direct access to the metal resulting in increased oxidation rates. Several authors have contributed to the development of the theory for oxide failure in tension [1-4], but there is little experimental data available, particularly for oxide scales at growth temperature $[1,5-6]$ to validate the proposed model of oxide failure.

Earlier work on iron oxide tested in tension at room temperature with a strain rate of $\sim 10^{-4} \mathrm{~s}^{-1}$ showed that equidistant cracks formed and the measured failure strains for a given oxide thickness only agreed with model predictions if due allowance was made for the residual cooling stress [7]. These results were compared with the findings of the present study which was undertaken to examine the tensile failure behaviour of iron oxide at $550^{\circ} \mathrm{C}$ (823K) using strain rates of $\sim 10^{-4}$ and $10^{-5} \mathrm{~s}^{-1}$ and the data were used to test the validity of the models. Failure was monitored using acoustic emission (AE) techniques and failures mechanisms were established in conjunction with optical and electron microscopy. 


\section{Experimental.}

Mild steel specimens (composition given in Tab. I), $200 \times 10 \times 1.5 \mathrm{~mm}$, were prepared from cold rolled sheet and ground to a 600 grit finish using $\mathrm{SiC}$ paper. After cleaning with alcohol, the specimens were coated with Berkatekt 12 stop-off paint (Acheson Colloids, U.K.) leaving an area of $10 \times 10 \mathrm{~mm}$ exposed on which an island of oxide was grown selectively. It had been shown previously that the coating did not influence the failure behaviour or the structure of the oxide [8]. The samples were positioned in a bend test furnace with a ceramic 4-point assembly (roller distance $20 / 40 \mathrm{~mm}$ ) so that the oxide was grown on the bottom surfaces between the inner rollers. The bend test furnace was placed in an Instron TML table model tensile test machine. After oxidation the furnace door was opened and the protruding specimen end was cooled with pressurized air before a broadband AE transducer type WD (Physical Acoustics Ltd, USA) was attached with a specimen clamp of $5 \mathrm{~N}$ force. Constant strain rates of $\sim 10^{-4}$ and $10^{-5} \mathrm{~s}^{-1}$ were then applied by lowering the crosshead. The $\mathrm{AE}$ monitoring system and the procedure used for establishing the thresholds of 45 and $48 \mathrm{~dB}$ for oxides $<30 \mu \mathrm{m}$ and $\geq 30 \mu \mathrm{m}$ thick, respectively, have been described elsewhere [8]. The specimens were cooled at a rate of $8{ }^{\circ} \mathrm{C} \mathrm{min}{ }^{-1}$ immediately after deformation.

Table I. - Chemical composition (element weight\%).

\begin{tabular}{|c|c|c|c|c|c|c|c|}
\hline $\mathrm{Al}$ & $\mathrm{Si}$ & $\mathrm{S}$ & $\mathrm{Mn}$ & $\mathrm{Mo}$ & $\mathrm{Cr}$ & $\mathrm{Ni}$ & $\mathrm{Fe}$ \\
\hline 0.17 & $<0.07$ & $<0.25$ & 0.50 & $<0.6$ & $<0.12$ & $<0.19$ & $\mathrm{Bal}$ \\
\hline
\end{tabular}

The oxide surfaces were examined microscopically after testing and cross sections were cold mounted in Epofix or hot mounted in Bakelite, ground and polished using very light pressure to a final finish of $1 \mu \mathrm{m}$ diamond.

\section{Results and discussion.}

3.1 MicrosCOPIC OBSERVATIONS. - Oxide scales consisted of an outer layer of haematite and an inner layer of magnetite. Growth and/or cooling stresses resulted in small wrinkles in the haematite layer at the surface of oxides $<10 \mu \mathrm{m}$ thick (Fig. 1a) and in a few instances with oxides between 10 and $20 \mu \mathrm{m}$ thickness. Deformation enlarged the wrinkles due to the effects of the Poisson's ratio which introduced a compressive stress normal to the applied stress. The number of wrinkles increased with deformation and the wrinkles acted in many cases as crack initiators.

A number of tests showed buckled areas with the whole oxide detached from the substrate (Fig. 1b) and in a few cases detached layers had actually spalled off. The occurrence of buckling and spalling was variable and difficult to relate to experimental parameters.

Tensile cracks normal to the direction of applied strain were found in all tests. Two types of cracks were observed, (i) long cracks which were longer and straighter the thicker the oxide (Fig. 1c-d) and (ii) short cracks between the long cracks mainly in thin oxides ( $\leq 20 \mu \mathrm{m}$ thick). The number of short cracks decreased rapidly with increasing oxide thickness (Fig. Ic-d). The smaller strain rate of $\sim 10^{-5} \mathrm{~s}^{-1}$ resulted in a higher crack spacing but cracks were very 

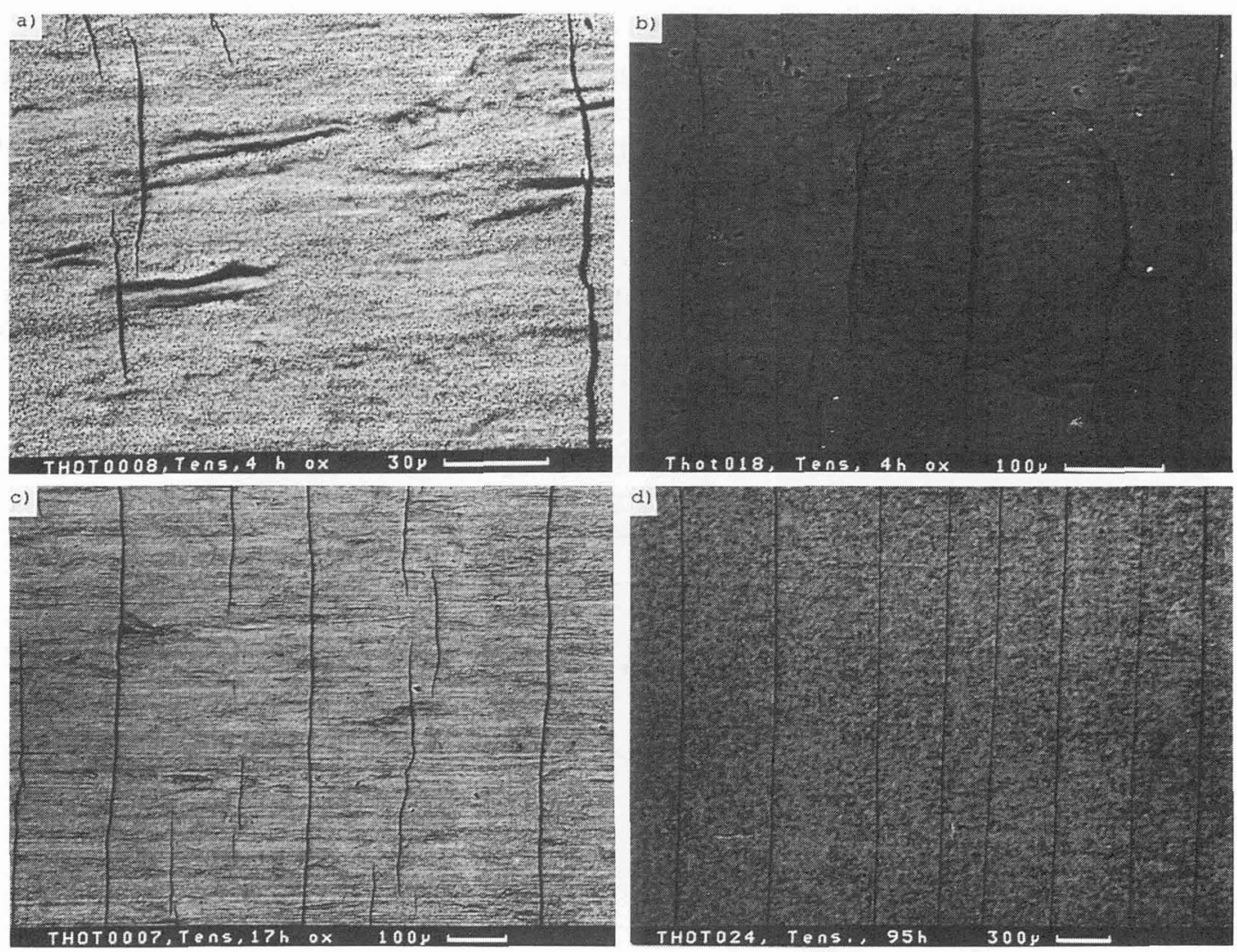

Fig. 1. - SEM surface photographs showing (a) wrinkles and tensile cracks (oxide thickness $5 \mu \mathrm{m}$, maximum strain $1.12 \%)$, (b) a buckled area $(6.0 \mu \mathrm{m}, 1.12 \%)$, (c) long and short cracks $(9.0 \mu \mathrm{m}, 1.12 \%)$, (d) long cracks $(46.0 \mu \mathrm{m}, 0.56 \%)$.

similar, except that very thin oxides $\leq 7 \mu \mathrm{m}$ thick showed predominantly short cracks. For oxides of similar thickness, crack spacing was higher when strained at growth temperature. At growth temperature, an equilibrium crack spacing was achieved for oxides $>20 \mu \mathrm{m}$ thick at strains $>0.60 \%$, indicating that these samples had already passed the transition from additional cracking to interface delamination. In oxides $>10 \mu \mathrm{m}$ thick and tested at room temperature the transition was between 0.6 and $1.12 \%$ strain. Thus the crack spacing could decrease further for oxides $<10 \mu \mathrm{m}$ or $<20 \mu \mathrm{m}$ thick tested at room temperature and growth temperature, respectively, so that the best fit lines go through the origin as would be expected from equation (1). In all cases, the crack spacing increased with oxide thickness in agreement with a model assuming that interfacial slip or plastic deformation of the substrate at the crack tip occurs. The maximum strain sustained in the middle of an oxide layer is that supported by interfacial slip which gives a crack spacing, $d$, of $[7,9]$

$$
d=\frac{k h \sigma_{\mathrm{ox}}}{\tau_{\mathrm{y}}}
$$

where $h$ is the oxide thickness, $k$ a numerical factor between 2 and 4 which depends on 
the shear stress distribution in the oxide area, $\sigma_{\mathrm{ox}}$ is the tensile strength of the oxide and $\tau_{\mathrm{y}}$ is the shear strength of the interface. The ratio $r=\sigma_{\mathrm{ox}} / \tau_{\mathrm{y}}$ determines the slope of the curves in figure 2 and is indicative of the relative shear strength of the interface. Evidence for $\mathrm{Al}_{2} \mathrm{O}_{3}$ shows that the tensile strength does not change significantly up to $600{ }^{\circ} \mathrm{C}[10]$. Although iron oxide is less creep resistant, it has been assumed that the tensile strength of the oxide would be the same at room and at growth temperature. It follows from the data shown in figure 2 that the shear strength of the interface must be approximately four times higher at room temperature than at growth temperature. This observation was supported by the appearance of all samples tested at temperature and hot mounted in Bakelite where shrinkage of the Bakelite had pulled the oxide from the metal substrate (Fig. 3a), whereas this was not so for samples tested at room temperature and mounted in the same way.

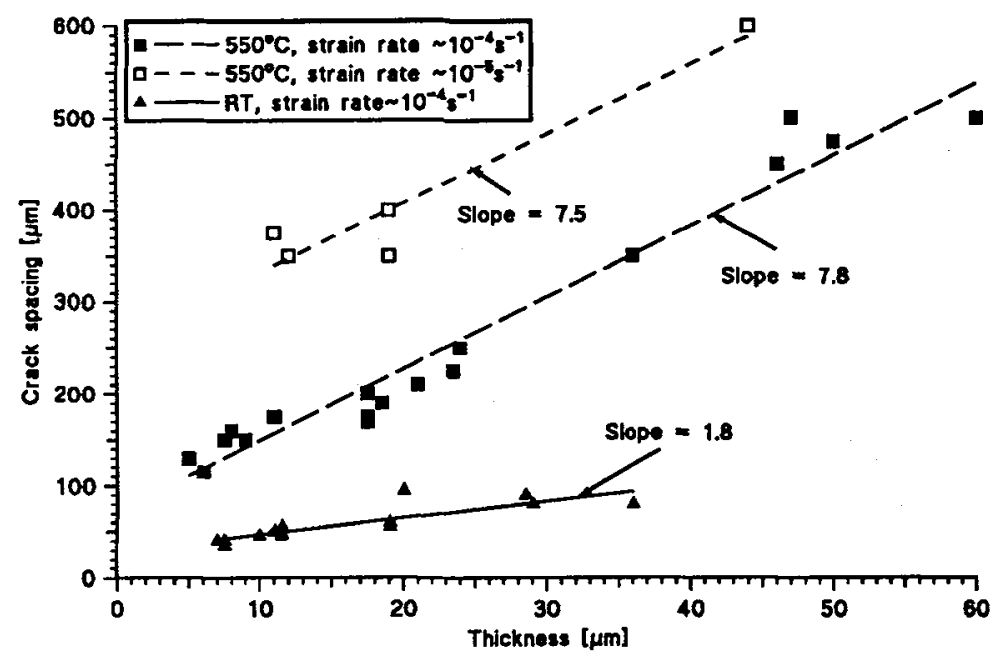

Fig. 2. - Crack spacing as a function of oxide thickness.

It can also be seen from figure 2 that the ratio $\sigma_{\mathrm{ox}} / \tau_{\mathrm{y}}$ is independent of strain rate, i.e. the tests with different strain rates at growth temperature had the same slope. However, the crack spacing was larger with a strain rate $10^{-5} \mathrm{~s}^{-1}$ presumably due to time dependent slip at the oxide/metal interface and/or due to creep in the oxide which allowed additional deformation of the oxide.

Although many cracks appeared to only partly penetrate the scale (Fig. 3a-b), sulphidation experiments performed to decorate cracks after deformation indicated that the whole thickness of the scale had been penetrated (Fig. 3c-d). Crack repair apparently occurred after deformation at growth temperature by crack closure during unloading and subsequent healing during cooling.

3.2 ACOUSTIC EMISSION RESULTS. - A maximum in the rate of AE energy counts was recorded in all tests shortly after the onset of cracking (Fig. 4), and this was ascribed to the creation of equidistant cracks in the oxide. In no case was there an increase in $\mathrm{AE}$ towards the end of the test due to interface delamination as observed in previous work at room tem- 

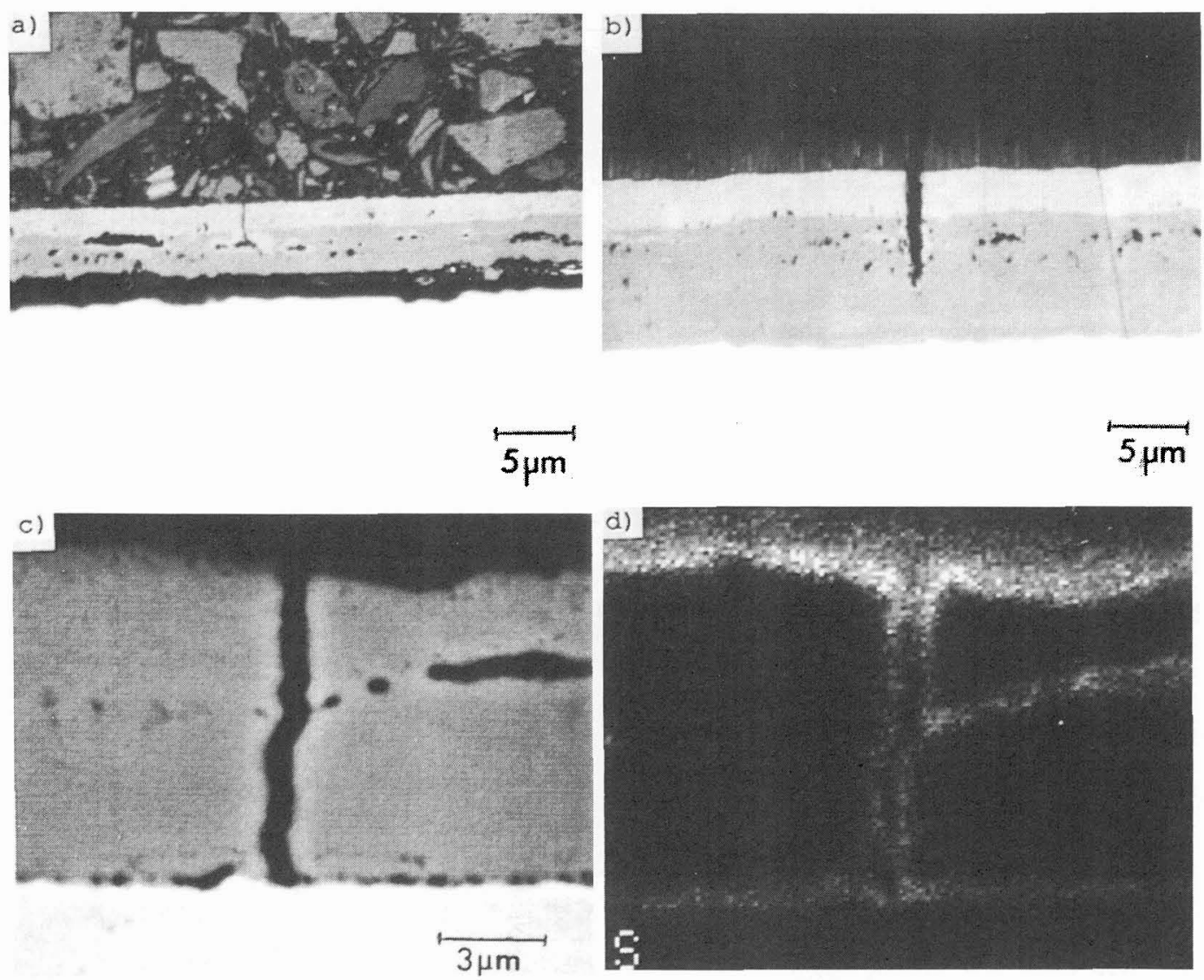

Fig. 3. - Cross sections showing (a) a $19 \mu \mathrm{m}$ thick oxide mounted in Bakelite (void size $0.4 \mathrm{~h}$, maximum strain $0.56 \%$ ), (b) a $49 \mu$ m thick oxide mounted in Epofix $(0.1 \mathrm{~h}, 0.56 \%$ ), (c) a $12 \mu \mathrm{m}$ thick oxide after sulphidation (1.12\%) and (d) the sulphur concentration.

perature [7], supporting the earlier evidence of lower interfacial strength and hence lower AE energy release from interface delamination at growth temperature.

Analysis of the AE signals carried out at a strain level of $0.30 \%$ above the measured failure strain, when all tests had already passed the maximum rate of $\mathrm{AE}$, showed that the cumulative number of AE energy counts increased with increasing oxide thickness (Fig. 5a), due to the higher energy stored and subsequent release during cracking of thicker scales. The average number of AE energy counts was higher for tests performed at growth temperature using strains rates of $10^{-4}$ and $10^{-5} \mathrm{~s}^{-1}$ when compared to the tests at room temperature (Fig. $5 \mathrm{~b}$ ). This behaviour can be explained as follows.

Oxides tested at room temperature showed medium sized cracks producing AE signals of similar energy, hence the average energy count number increased only slightly with thickness in agreement with the linear increase of the new fracture surface area with thickness [7]. In contrast, when tested at growth temperature, cracks became longer as the oxide thickness increased, so that the average energy counts increased more rapidly at growth temperature than at room temperature, since the creation of new fracture surface area increased with both 


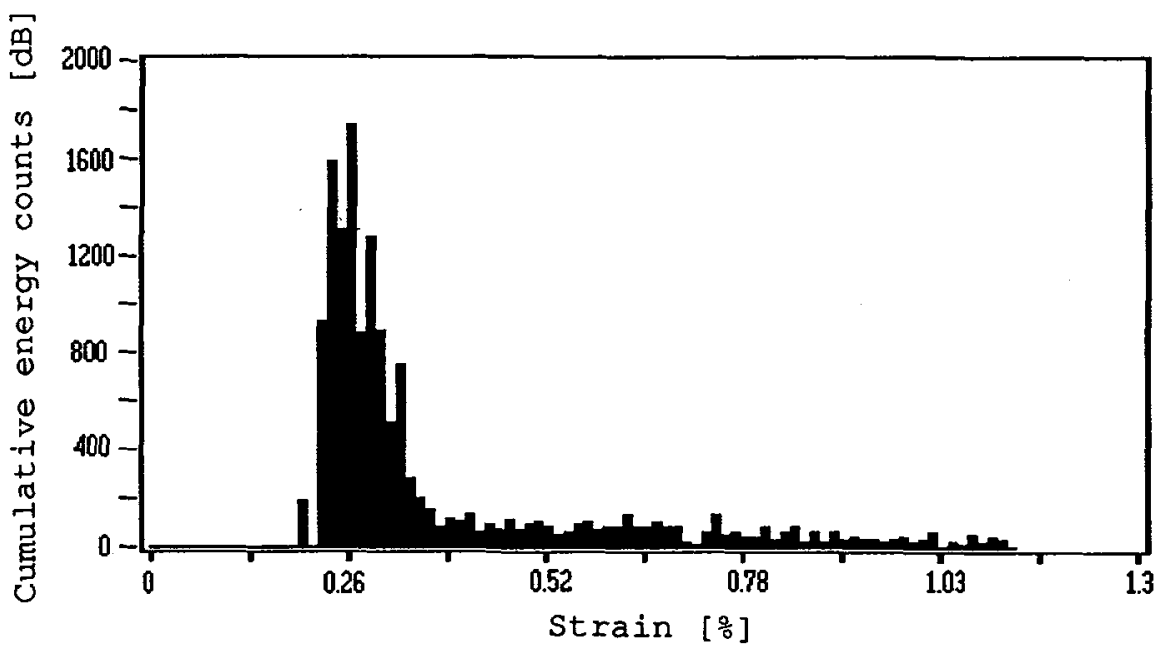

Fig. 4. - Histogram of the average $\mathrm{AE}$ energy counts as a function of strain for a $9.0 \mu \mathrm{m}$ thick oxide.

a)

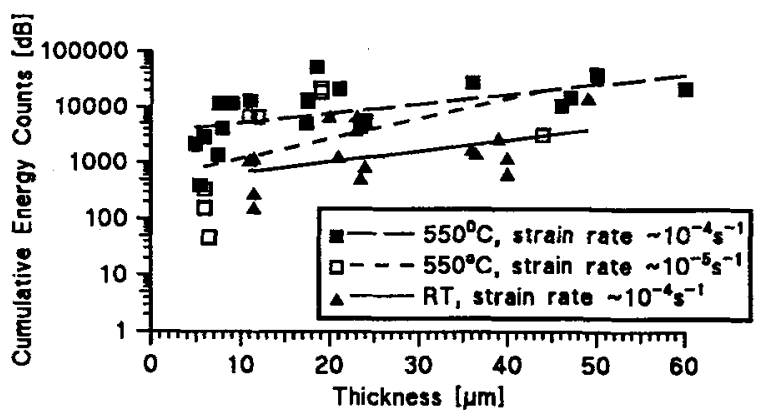

b)

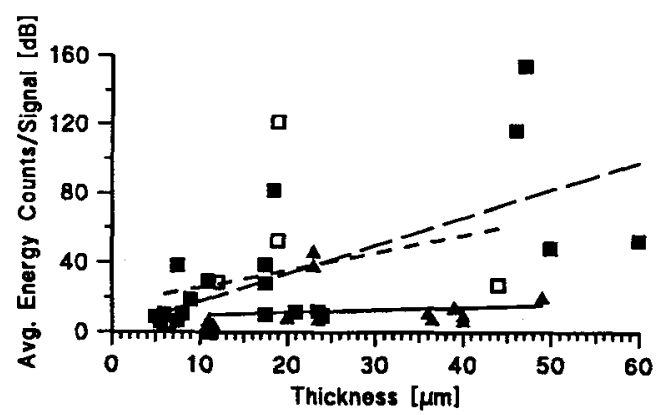

Fig. 5. - Plot of (a) cumulative and (b) average AE energy counts as a function of oxide thickness.

the thickness and the crack length. This was most noticeable in oxides $>25 \mu \mathrm{m}$ thick where the number of AE signals with energy count numbers $\geq 100 \mathrm{~dB}$ showed an almost one-to-one correlation with the number of cracks stretching across the whole specimen width.

3.3 OXIDE FAILURE STRAINS. - Earlier work had shown that macroscopic failure was marked by the occurrence of a high rate of $\mathrm{AE}$ or high energy $\mathrm{AE}$ signals and the first incidence of such events was used to calculate critical failure strains [7].

Figure 6a shows the measured failure strains as a function of oxide thickness for the tests at growth temperature with strain rates of $\sim 10^{-4}$ and $\sim 10^{-5} \mathrm{~s}^{-1}$ and these are compared with room temperature tests with a strain rate of $\sim 10^{-4} \mathrm{~s}^{-1}$. The variability in the data can be explained by a fracture mechanics analysis. For a comparison with predictions based on linear elastic fracture mechanics allowance has to be made for the different void sizes since 
the critical failure strain, $\epsilon_{\mathrm{c}}$, is $[3,4]$

$$
\epsilon_{\mathrm{c}}=\sqrt{\frac{2 \gamma}{F^{2} \pi E c}}
$$

where $\gamma$ is the surface fracture energy, $E$ is the Young's modulus, $F$ is a numerical factor depending on shape and position of the void and $c$ is the physical length of a surface void or half the length of an embedded void. In the limiting case, $c$ could be either thickness independent giving constant failure strains or directly proportional to thickness which results in thickness dependent failure strains [11]. In this case a relationship of the form $c=f h$, where $f$ is a constant and $h$ is the oxide thickness, can be inserted into equation (2) [4].

a)

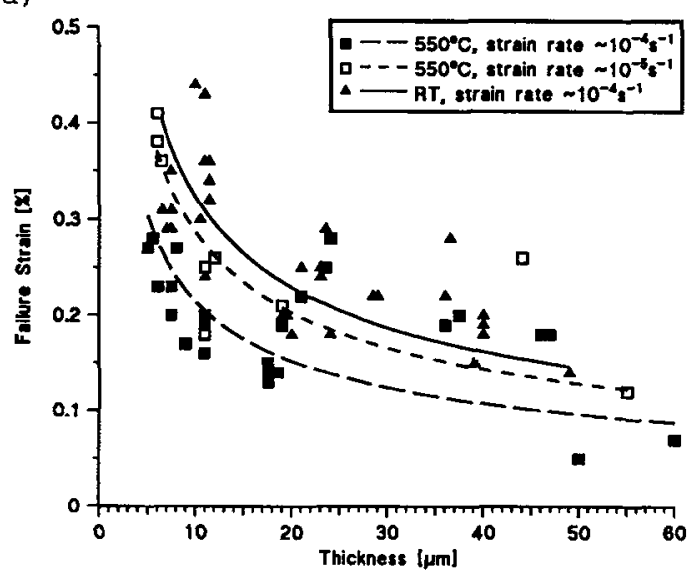

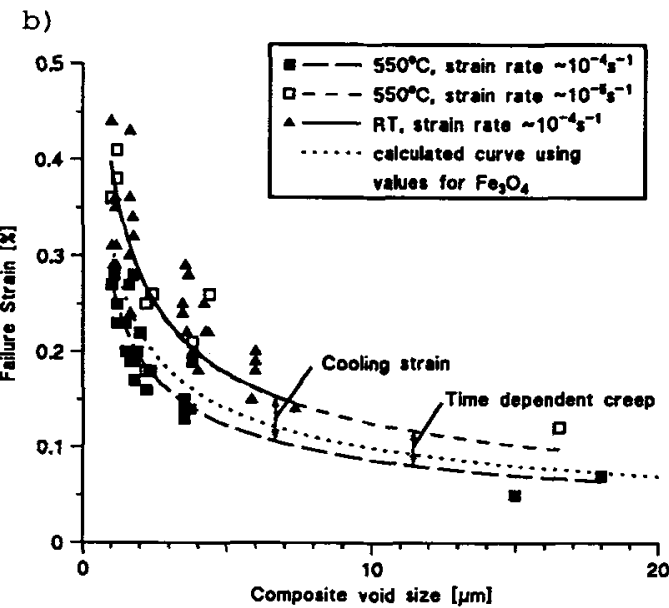

Fig. 6. - Measured failure strains as a function of (a) oxide thickness and (b) composite void size.

In the present study, the number of voids varied from one test to another even if carried out under the same conditions (cf. Fig. 3a-b) and could not be related to thickness. Thus the measured failure strains were plotted in figure $6 \mathrm{~b}$ as a function of composite void size. $F$ was 1.18 for an out-of-centre flaw of the length $0.4 \mathrm{~h}$ at a position of $\sim 0.4 \mathrm{~h}$ from the oxide surface [12] which was found in most oxides. The values of $4.5 \mathrm{~J} \mathrm{~m}^{-2}$ for $\gamma$ and $210 \mathrm{GPa}$ for $E$ of $\mathrm{Fe}_{3} \mathrm{O}_{4}$ were taken from reference [4]. Good agreement with the measured values was obtained for the chosen $F$-value. $c$ was estimated from an examination of the polished cross-sections and use of the composite void size approach [1]. However such methods of estimating void size are prone to error due to uncertainties in metallographic preparation methods. Importantly, the shape of the curve for measured data closely follows a power law expected from the fracture mechanics model (Fig. 6b). The difference in the critical failure strains at room and at growth temperature can be explained by compressive cooling stresses which must be overcome before the oxide experienced tensile stresses. Measurement of strain by X-ray diffraction on the same oxides gave an average strain values of $0.06-$ $0.07 \%$. Similarly, a calculation using thermal expansion coefficients for haematite, magnetite and the substrate given in reference [9] showed that the cooling strain was approximately $0.04-0.05 \%$, in agreement with that obtained from figure $6 \mathrm{~b}$. The higher failure strains for 
oxides tested at growth temperature with a strain rate of $10^{-5} \mathrm{~s}^{-1}$ compared to the tests with a strain rate of $10^{-4} \mathrm{~s}^{-1}$ were due to time dependent creep which is possible in magnetite under these conditions [3]. In addition, it is expected from figure $6 b$ that with a strain rate of $10^{-5} \mathrm{~s}^{-1}$ both the effects of the cooling strain and the creep relaxation during deformation would offset each other.

The experimental data were also used to determine fracture toughness values, $K_{\text {IC }}$. Plots of the form $\sigma_{\mathrm{c}}$ as a function of $1 /(\pi c)^{0.5}$, where $\sigma_{\mathrm{c}}$ is the failure stress are shown in figure 7 . The slope of the lines gives the $K_{\mathrm{IC}}$-values whereas the intercept on the stress axis gives a measure of the residual stress present in the oxide. Values of 1.07 and $1.06 \mathrm{MN} \mathrm{m}^{-3 / 2}$ for $K_{\text {IC }}$ were obtained in the tests at growth and room temperature, respectively. The residual growth stress at growth temperature was $23 \mathrm{MN} \mathrm{m}^{-2}$ (tensile). The difference of $184 \mathrm{MN} \mathrm{m}^{-2}$ between the intercept values for room and growth temperature tests is a measure of the compressive cooling stresses. Again, the lower strain rate gave an almost parallel line in the tests at growth temperature, as expected, since $K_{\mathrm{IC}}$ is a material parameter and is believed to be constant up to $\sim 600^{\circ} \mathrm{C}[1]$. In this case the difference in residual stress compared to the tests at growth temperature with a strain rate of $\sim 10^{-4} \mathrm{~s}^{-1}$ is an indication of the amount of creep in the oxide.

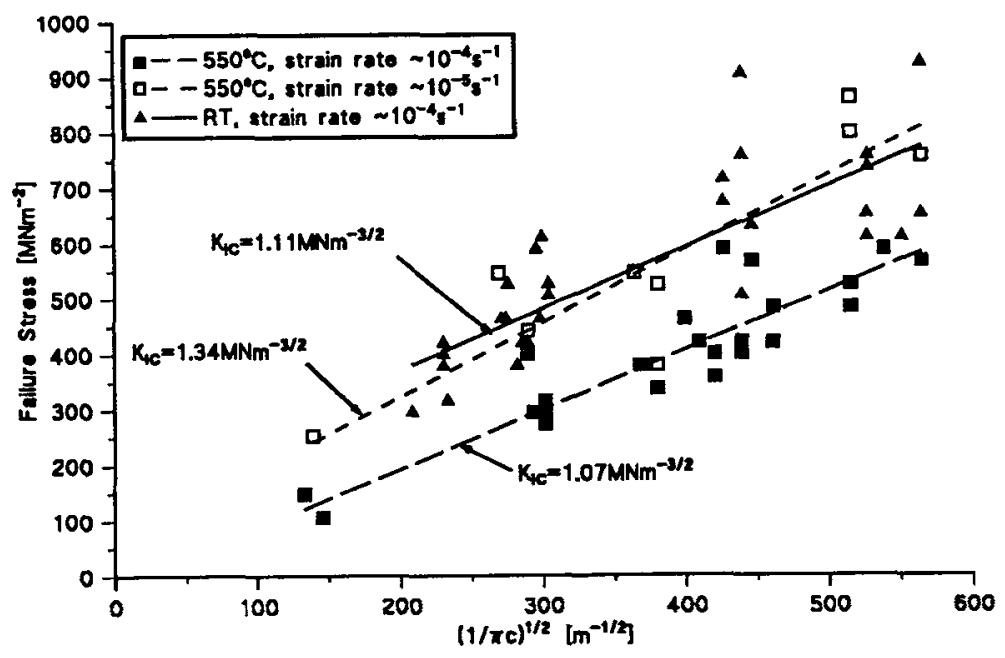

Fig. 7. - Fracture stress as a function of composite void size giving $K_{\mathrm{IC}}$ and residual stress, $\sigma_{\mathrm{r}}$.

It is obvious from the above analysis that the measured failure strain, $\epsilon_{\mathrm{m}}$, has various contributions according to the following relation:

$$
\epsilon_{\mathrm{c}}=\epsilon_{\mathrm{gr}}+\epsilon_{\mathrm{cool}}+\epsilon_{\mathrm{m}}+\epsilon_{\mathrm{pl}}
$$

where $\epsilon_{\mathrm{gr}}$ is the growth strain, $\epsilon_{\mathrm{cool}}$ is the cooling strain, $\epsilon_{\mathrm{c}}$ is the failure strain based on the fracture mechanics relationship (Eq. (2)), $\epsilon_{\mathrm{pl}}$ is the strain compensated by time dependent creep or lateral oxide growth [6]. 


\section{Conclusions.}

The $\mathrm{AE}$ technique has been successfully used to interpret the tensile failure mechanisms operating in thermally grown oxides subjected to 4-point bend tests at room and at growth temperature $\left(550^{\circ} \mathrm{C}\right)$. The main conclusions were:

1) Spacing between equidistant cracks increased linearly with thickness according to a model assuming interfacial slip. Larger crack spacing at growth temperature showed that the interfacial strength was lower than at room temperature.

2) The void size was critical for comparing measured failure strain with predictions based on a fracture mechanics model. Differences between room and growth temperature values were attributed to cooling strains.

3) A $K_{\mathrm{IC}}$-value of $1.1 \mathrm{MN} m^{-3 / 2}$ was obtained for the oxide.

4) The lower strain rate of $10^{-5} \mathrm{~s}^{-1}$ gave the same $K_{\mathrm{IC}}$-value, although crack spacing and failure strains were larger due to time dependent creep occurring under those conditions.

\section{Acknowledgements.}

The British Council provided a travel grant to Germany for M.M. Nagl and W.T. Evans. The European Community provided financial support under the BRITE/EURAM-Program for M.M. Nagl. The research reported in this paper was carried out as part of the "Environmental Degradation of Materials Programme" a programme of underpinning research financed by the UK Department of Trade and Industry.

\section{References}

[1] Hancock P., Nicholls J.R., Mat. Sci. Tech. 4 (1988) 398-406.

[2] Evans H.E., Mat. Sci. Eng. A 120 (1989) 139-146.

[3] Schuetze M., Mat. Sci. Tech. 6 (1990) 32-38.

[4] Robertson J., Manning M.I., Mat. Sci. Tech. 6 (1990) 81-91.

[5] Hancock P., Proc. of the Symp. on Stress Effects and the Oxidation of Metals, J.V. Cathcart Ed. (USA, AIME, 1974) 155-176.

[6] Schuetze M., Oxid. Metals 24 (1985) 199-232.

[7] Nagl M.M., Hall D.J., Evans W.T., Proc. of the NAGE Conference on Life Prediction of Corrodible Structures (Houston, NACE, 1992).

[8] Nagl M.M., Evans W.T., Saunders S.R.J., Hall D.J., to be submitted to Mater. Sci. Technol.

[9] Armitt J., Holmes D.R., Manning M.I., Meadowcroft D.B., Metcalfe E., EPRI-Report FP-686 (Palo Alto, California, Electric Power Research Institute, 1978).

[10] Morrell R., Handbook of Properties of Technical and Engineering Ceramics: Part II (UK, HMSO, 1987).

[11] Osgerby S., Dyson B.F., Mat. Sci. Tech. 6 (1990) 2-8.

[12] Tada J., Paris P.C., Irwin G.R., Stress Analysis of Cracks-Handbook (St. Luis, Paris Productions, 1974). 